This is an Accepted Manuscript of an article published by Taylor \& Francis Group in Cataloging and Classification Quarterly on May 14, 2019, available

online: http://www.tandfonline.com/10.1080/01639374.2019.1602091

(C) 2019 Taylor \& Francis Group. Personal use of this material is permitted. Permission from Taylor \& Francis Group must be obtained for all other uses, in any current or future media, including reprinting/republishing this material for advertising or promotional purposes, creating new collective works, for resale or redistribution to servers or lists, or reuse of any copyrighted component of this work in other works.

To cite this article:

Nurhak Tuncer \& Reed David (2019): The Cataloging of Self-Published Items, Cataloging \& Classification Quarterly, DOI: 10.1080/01639374.2019.1602091 


\title{
The Cataloging of Self-Published Items
}

\section{NURHAK TUNCER \\ Elizabeth City State University, Elizabeth City, North Carolina, USA}

\section{REED DAVID}

\section{Washington State University, Pullman, Washington, USA}

\begin{abstract}
This article presents the results of a survey conducted in the fall of 2015 of librarians who are cataloging self-published items. The survey was conducted in response to the growing popularity of self-publishing and the increasing prevalence of self-published items in libraries. Survey respondents were asked to describe how they are cataloging these items and provide representative examples of the records they have created. An analysis of both the survey responses and the records is presented, followed by suggestions for best practices for cataloging these items.

KEYWORDS:

Self-publishing, cataloging, surveys, cataloging research, cataloging best practices

Acknowledgments: Karen Snow, Jean Harden, Kevin Kishimoto, Mark Scharff, Beth Iseminger
\end{abstract}

\section{INTRODUCTION}

From books to musical scores to audio and video recordings, self-publishing has exploded in popularity in recent years and self-published items have begun to make their way into all types of libraries. Cataloging these items can be challenging, though, usually because they tend to have vague or incomplete publication information on them. Such items usually need either original cataloging or highly complex copy cataloging and generally require at least some outside research in order to be properly cataloged. In this article, these challenges are presented 
and discussed in detail after careful analyses of a survey and the MARC records that were submitted by the survey respondents.

The authors began working together on this topic in March 2015. They realized that most of what little has been written in the library literature on self-publishing is from the collectionmanagement perspective, with almost nothing available from the cataloging perspective. To address the challenges posed by self-published items, the authors conducted a survey of primarily U.S. librarians to analyze how they are cataloging these items. Launched on September 14, 2015 and closed on December 31, 2015, the survey asked catalogers to describe how they are cataloging self-published items and provide representative examples of the records they have created. The authors analyzed both the survey responses and the records to determine what the current trends are in the cataloging of these items. They presented their analyses at various professional conferences between October 2015 and August $2016 .{ }^{1}$

The goal of the authors' work is descriptive and not proscriptive. They want to learn more about how self-published items are being cataloged in libraries today, get the library community talking about this topic, and shed light into areas that may need further research. It is hoped that this article will make clear that the library community needs to have a conversation about cataloging self-published items. The authors would like to see this conversation lead to the creation of best practices for cataloging self-published items, so that they may be as visible and accessible as possible for library users.

\section{THE DEFINITION OF SELF-PUBLISHING}

Defining self-publishing is important for catalogers as well as for the authors of this article, since it defines the scope of this research project. It is definitely more than a simple dictionary definition; Merriam-Webster defines the word self-publish as "to publish (a book) 
using the author's own resources." At the very least, the portion in parentheses should read "(a book or other media)," given that items in all formats can be self-published. Even with this addition, this is a vague definition. After careful observation, though, the authors of this article have agreed on a fuller definition of self-published items. They define them as items for which the creators had control over most or all of the many stages of the publication process. These stages begin with content creation and editing, continue with designing the items' packages and marketing the items (frequently on the website of the creator or the self-publishing firm), and end with the production and distribution of the items. Not all of the stages have to be completed by the creator in order for the item to be self-published, but a majority of them should be. For instance, the creator can do everything else themselves, but may leave the production up to a print-on-demand firm, the distribution up to a commercial distributor, or both. In this instance, since a majority of the stages of the publication process were completed by the creator, the authors would define the item as self-published.

Self-published items are frequently born digital and may only be available online via print-on-demand through a commercial distributor or on the creator's website. However, one should keep in mind that not all print-on-demand items are self-published, nor all self-published items are print-on-demand. Print-on-demand as an action itself is certainly a related topic to selfpublishing, because print-on-demand is sometimes the last stage of the self-publication process. However, the authors of this article are mainly interested in how all of the stages of the selfpublication process are reflected in the library catalog, not just the last stage.

The definition of self-publishing is important for catalogers for several reasons. If a cataloger knows who did what to bring a self-published item into existence, or at least has an idea of how much control the creator had over the self-publication process, one can catalog the 
item more effectively. Who is responsible for which stages of the self-publication process can vary between different self-publishing firms and sometimes even between different versions or copies of an item. It strongly affects how publication information is presented on the item, which in turn affects how that information (provenance, publication data, anything that improves the item's visibility) would be recorded in a catalog record. In general, no matter how one defines it, self-publishing is becoming a fact of life for libraries and librarians, as each day more creators want to self-publish and more self-published items are making their way into libraries.

\section{LITERATURE REVIEW}

There is a growing body of work in the library community on self-publishing. Most of what has been done so far has been focused on the topic from the collection-management perspective, dealing with questions of how to find, acquire, and preserve such items. The literature about how to catalog self-published items has been sparse. Despite this situation, there are a number of articles and conference presentations that can be used as a foundation to build on this topic.

Michael Saffle wrote an article on self-publishing in musicology that also offered a brief overview of the history of self-publishing in general. He mentioned a number of famous works that were self-published by their creators. The specific works he mentioned include John Milton’s book Areopagitica (1644), Upton Sinclair's book Money Writes! (1924), Carl Philipp Emanuel Bach's Kenner und Liebhaber sonatas (1779-1787), and Georg Philipp Telemann's Six Trios of $1718 .{ }^{3}$ His article is a reminder that, as popular as it is today, self-publishing is not a new phenomenon and has existed in various forms for centuries. In recent decades, though, technological advancements have drastically changed self-publishing and libraries need to pay closer attention to it. 
Juris Dilevko and Keren Dali took a closer look at self-publishing than Saffle did, examining the manner in which libraries are collecting self-published books. Like Saffle, they gave a list of famous authors who self-published, a list that includes William Blake, Elizabeth Barrett Browning, Willa Cather, W. E. B. DuBois, Benjamin Franklin, Nathaniel Hawthorne, Beatrix Potter, Mark Twain, Walt Whitman, and Virginia Woolf. Their method involved searching OCLC WorldCat for books published by seven of the best-known self-publishing firms. The specific areas of the catalog records they considered included firm names, subject headings, and the number and types of libraries that have holdings on the records. ${ }^{4}$

Jana Bradley, Bruce Fulton, and Marlene Helm studied the cataloging of self-published items. They searched WorldCat for self-published books, much as Dilevko and Dali did, albeit on a larger scale, as they considered a randomly selected sample of the output of ninety-three self-publishing firms and investigated the results from a number of angles. One of the angles they considered was cataloging; they looked at presence or absence of ISBNs, encoding levels, and near-matches. ${ }^{5}$ Their article is significant because it lists self-publishing firms, observes the items they publish, and examines some missing publication information on these items. The authors of this article also analyzed the WorldCat records gathered in their survey to identify the patterns in these records.

Robert P. Holley provided an overview of the state of bibliographic control, including cataloging, of self-published items. His book chapter emphasizes sources of bibliographic control other than individual catalogers creating traditional records, including the Library of Congress Cataloging Distribution Service, distributors' websites, and catalog records created by distributors. In particular, he describes an announcement by Smashwords and OverDrive, distributors of e-books whose products include self-published e-books, that they will provide 
MARC records for their e-books as "[t]he most exciting news for improved bibliographic control of self-published works[.]" ${ }^{\prime 6}$ Left unsaid are the quality of these records, as well as how much cleanup they may require from individual catalogers.

Librarians are starting to bring creators of self-published items into the conversation. The Reference and User Services Association (RUSA) created an online Library Publishing Toolkit to support libraries that engage in publishing initiatives. ${ }^{7}$ Heather Moulaison Sandy discussed a self-publishing initiative at a public library in suburban Kansas City, Missouri. ${ }^{8}$ Both the RUSA toolkit and Sandy's article focus on how to support content creators. This is an idea whose time has come, as more and more libraries aim towards educating content creators in copyrighting, publishing, designing, and marketing their items. The involvement of libraries in this process can also lead to better cataloging of these items.

The contemporary self-publishing phenomenon includes formats other than printed books. One such format is the zine, which is defined by Merriam-Webster as "a noncommercial often homemade or online publication usually devoted to specialized and often unconventional subject matter." ${ }^{\prime 9}$ Zine creators generally complete every stage of the publication process themselves, making zines self-published. Heidy Berthoud has written about the creation of the zine collection at Vassar College, including its cataloging. Zines present a variety of cataloging challenges, from lacking International Standard Serial Numbers to not having basic bibliographic information to occasionally beginning as monographs before becoming serials. Librarians who catalog zines are working on a metadata standard and union catalog for them in order to improve their cataloging. ${ }^{10}$ Zines are not the only format of self-published items that would benefit from specialized cataloging rules. 
Kent Underwood wrote an article on self-published music scores that deals with them solely from the collection-management perspective. Contemporary composers are increasingly publishing their own scores and making them available through their personal websites, often as PDFs or via print-on-demand. Underwood is particularly concerned with the impermanence of these websites, which can cause libraries to miss opportunities to preserve these scores and to document contemporary musical culture. He is also concerned with figuring out how to find these scores, since these composers do not publish through well-known vendors that libraries use. Therefore, it is a challenge for libraries to obtain these items. ${ }^{11}$ Underwood's research shows that libraries need to reconsider and change their collection management strategies in order to include such scores as well. However, scores are not the only music format that is self-published. Self-published recordings are becoming increasingly popular, particularly in music genres such as jazz, popular music, and folk music. Recordings in these genres tend to be the primary document, when scores are usually absent and recordings are often the only way of manifesting the works. Catalogers working with recordings in these genres must keep in mind that the recording and anything associated with it, such as CD liner notes, may be the sole source of information they can use for transcribing data and creating bibliographic records for these works. Music catalogers are dealing with self-published items and topics closely related to them as well, as shown in two recent presentations at music library conferences. Charles Peters discussed the workflows used by his library and other libraries for music scores that are available only as PDFs, most of which are self-published. From selection and acquisition to cataloging, preservation, and circulation, these workflows differ drastically from those for scores published in print. He intends to conduct a survey on this topic and create a final report for use by libraries developing their own workflows for such scores. ${ }^{12}$ Anne Adams and Morris Levy presented on 
the cataloging of print-on-demand music scores, which, as mentioned above, is related to selfpublishing. In their presentation, they explain how they believe such music scores should be cataloged, using records they have created as case studies on this topic and offering them as templates for best practices. ${ }^{13}$ Their work supports the authors' assertion that these items are challenging to catalog, particularly when one is recording the publication information. Peters's, Adams's, and Levy's presentations focus on the last stage of the self-publication process in general and print-on-demand in particular. They feature the very first examples of case studies in music and could be used as a foundation for best practices for self-published items and pave the way to better cataloging practices for all formats of such items.

The articles and presentations described in this literature review show that self-publishing has implications for all types of libraries, not only in terms of cataloging, but also acquiring and preserving self-published materials and finding ways to support content creators in publishing their own materials. The authors of this article hope to contribute to the evolving library literature on this topic with the analysis of their survey on the cataloging of such materials. This survey proves that catalogers are making a sincere effort to catalog self-published items, and the results represent a collective response and voice of these catalogers. The patterns found in the survey results may lead catalogers to find better ways to catalog such items.

\section{METHODOLOGY}

The authors conducted a survey of primarily U.S. librarians to analyze how they are cataloging self-published items. They created the survey with the survey program Qualtrics. The final version of the survey was launched after getting approval and passing the institutional review board (IRB) requirements in order to follow the ethics protocols and protect the confidentiality of individuals who took the survey. It consisted of twelve quantitative and 
qualitative questions, all of which had text boxes for survey respondents to provide additional comments. The survey was launched on September 14, 2015, closed on December 31, 2015, and completed by 403 people. Once it was open, the survey was distributed over six electronic discussion lists and through four Facebook groups. The lists used were the lists of the Music Library Association, Music OCLC Users Group, and Online Audiovisual Catalogers, the Association for Library Collections and Technical Services' Central list, and the lists RDA-L and Autocat. The Facebook groups used were Library Think Tank - \#ALATT (then known as ALA Think Tank), Music Librarians, RDA Cafe, and Troublesome Catalogers and Magical Metadata Fairies. Once the survey was closed, the results were exported into a spreadsheet and analyzed by the authors. A separate spreadsheet was created to analyze the data from the survey's eleventh question, in which the authors analyzed WorldCat records that were submitted by survey respondents.

\section{SURVEY RESULTS}

\section{Introductory Questions}

The survey began with three questions about the respondents' work in general and their work with self-published items in particular. These questions were asked in order to give the authors more ways to analyze the survey results. The first question asked the respondents to identify the type of library where they work. As shown in table 1, "academic" was the top response, although all types of libraries had some responses. This is a reminder that looking for better ways to catalog self-published items is every library's concern.

\section{Table 1.}

\begin{tabular}{|l|l|l|}
\hline \multicolumn{1}{|l|}{ 1. What type of library do you currently work for? } \\
\hline Answer & Response & Percentage \\
\hline Academic & 181 & $45 \%$ \\
\hline Public & 138 & $34 \%$ \\
\hline
\end{tabular}




\begin{tabular}{|l|l|l|}
\hline Special & 26 & $6 \%$ \\
\hline Archives & 3 & $1 \%$ \\
\hline School & 5 & $1 \%$ \\
\hline Other (please specify) & 48 & $12 \%$ \\
\hline Total & 401 & $100 \%$ \\
\hline
\end{tabular}

The second question concerned whether respondents catalog self-published items in their local or consortial databases or in a database, such as WorldCat, shared beyond a consortium. It was asked to determine how accessible their records are. More than a quarter of respondents are only cataloging these items locally (table 2).

Table 2.

2. Do you catalog self-published items locally/consortially or in a database (e.g. OCLC) shared beyond a consortium?

\begin{tabular}{|l|l|l|}
\hline Answer & Response & Percentage \\
\hline Local/consortial & 109 & $27 \%$ \\
\hline Shared beyond a consortium & 129 & $32 \%$ \\
\hline Both & 152 & $38 \%$ \\
\hline Other (please specify) & 11 & $3 \%$ \\
\hline Total & 401 & $100 \%$ \\
\hline
\end{tabular}

The third question was about formats. The authors wanted to know what formats of selfpublished items are being cataloged in addition to books, so that later in their research they could focus on each format in more detail. In this question, "Books" was the top response (table 3), but other formats had strong showings as well, including music formats. "Sound recordings" was the second-most popular response, with "Musical scores" not far behind. Indeed, every format received its fair share of answers, which underlines the point from the first question, namely that self-published items are every library's concern.

Table 3.

\section{What format(s) of self-published items do you catalog? (check all that apply)}




\begin{tabular}{|l|l|l|}
\hline Answer & Response & Percentage \\
\hline Books & 379 & $94 \%$ \\
\hline Musical scores & 64 & $16 \%$ \\
\hline Sound recordings & 153 & $38 \%$ \\
\hline Video recordings & 146 & $36 \%$ \\
\hline Electronic resources & 79 & $20 \%$ \\
\hline Serials & 61 & $15 \%$ \\
\hline Other (please specify) & 23 & $6 \%$ \\
\hline
\end{tabular}

\section{Publication Information Questions}

The next three questions asked respondents how they record publication information for items from self-publishing firms. Each question corresponded to one of the common subfields seen in the MARC 260 and 264 fields. The first two questions included answers that involved entering information in brackets, which is the common thing to do when the information comes from outside of the item being cataloged or when the information is not taken from the preferred source of information.

The first of these questions was about how catalogers record the publisher, information that is generally found in MARC 260/264 subfield b. A cataloger could consider either the firm or the creator to be the publisher of a self-published item based on the information found on the item itself or from outside research. With this in mind, the authors came up with a number of possible scenarios, some with the creator, some with the firm, some with brackets, some without. As shown in table 4, the most popular answer was "Other (please specify)," which shows a lack of clarity in this area. The authors of this article wanted to know how catalogers usually handled the absence of publisher information. Do they prefer to put the creator name or the firm name in the publication area or just put "Publisher not identified" in brackets? The survey results show that very few respondents are routinely using "Publisher not identified" in brackets. A majority 
of the catalogers were not leaving this area blank by choosing between the creator or the publishing firm as the publisher. The authors analyzed the MARC records collected in the survey's eleventh question and compared them to the responses to this question. They have seen that the best examples of records have both the creator and the firm names transcribed in the record.

Table 4.

\begin{tabular}{|l|l|l|}
\hline 4. How do you record the publisher? & \multicolumn{2}{l|}{} \\
\hline Answer & Response & Percentage \\
\hline Firm name, in brackets & 42 & $11 \%$ \\
\hline Creator name, in brackets & 70 & $18 \%$ \\
\hline [Publisher not identified] & 39 & $10 \%$ \\
\hline Firm name, not in brackets & 113 & $28 \%$ \\
\hline Other (please specify) & 133 & $34 \%$ \\
\hline Total & 397 & $100 \%$ \\
\hline
\end{tabular}

This question had a text box for additional thoughts on this topic, shown below, and those thoughts were similarly varied. The creator name, both in brackets and not, was used in place of the publisher very frequently.

Question 4: Selected text box responses

"If the publisher information isn't there, I use my best judgment AND brackets." "Usually creator name, unless creator name is unclear; then Firm name in brackets."

"Not easy. Usually use the author since they probably paid to have it printed." "I consider firms like Createspace to be publishers."

"If the firm name is prominent, I use that. If not, I use creator name."

The second of these three questions concerned recording the place of publication (MARC 260/264 subfield a). The goal of asking this question was to see whether the firm location or where the author lives could be substituted for the publisher's location. Responses to this question paralleled responses to the previous question to a significant extent in terms of having the same problem of lacking publication information on the items. "Firm location, not in 
brackets" and "Where the author lives, in brackets" had strong showings, but again, "Other (please specify)" was the top response (table 5).

Table 5.

\begin{tabular}{|l|l|l|}
\hline 5. How do you record the place of publication? & Response & Percentage \\
\hline Answer & 64 & $16 \%$ \\
\hline Firm's location, in brackets & 65 & $16 \%$ \\
\hline Where the author lives, in brackets & 57 & $14 \%$ \\
\hline [Place of publication not identified] & 81 & $21 \%$ \\
\hline Firm's location, not in brackets & 127 & $32 \%$ \\
\hline Other (please specify) & 394 & $100 \%$ \\
\hline Total & \\
\hline
\end{tabular}

As with the previous question, the text box answers to this question, shown below, were highly varied. Catalogers are struggling with the question of whether or not to use the printing location in this field, since the publication location is frequently missing but the printing location may be available.

\section{Question 5: Selected text box responses}

"If a place is indicated on the item, I record it; if not, I conjecture at least to the country. I absolutely never use [Place of publication not identified]."

"The place has been confusing. I started using the printing location in brackets. But I have since decided [United States] would be better."

"Never use [place of publication not identified] if it can be avoided."

The last of these three questions pertains to recording the date of publication (MARC 260/264 subfield c). The authors asked this question because, in their own work, they observed that the publication date of these items is usually not clear, mainly because an actual publication date is absent most of the time, leaving them to use a copyright or printing date instead. They wanted to know how other librarians handled this situation. The survey responses also show that the publication date is not entirely clear on such items (table 6). 
Table 6.

\begin{tabular}{|l|l|l|}
\hline \multicolumn{2}{|l|}{ 6. When recording the date of publication, is that date usually clear or unclear? } \\
\hline Answer & Response & Percentage \\
\hline Clear & 212 & $55 \%$ \\
\hline Unclear & 171 & $45 \%$ \\
\hline Total & 383 & $100 \%$ \\
\hline
\end{tabular}

This question's text box responses, shown below, align with the survey responses. Some catalogers resort to an outside source, such as Amazon, to answer this, but more used the copyright or printing date to infer a publication date.

Question 6: Selected text box responses

"I tend to use outside resources, such as Amazon, to identify a date of publication."

"There is usually at least a copyright date from which to infer a publication date." "Since we are not using RDA, we include only the copyright date (when given), not the date of publication."

"Sometimes, I infer the date of printing (left corner at the bottom of the last page) as date of publication. If there is a copyright date available, I use that date, instead."

"I usually need to infer a publication date from the date of manufacture or copyright date-when I do so, I record the date of publication in brackets."

\section{Questions Related to Cataloger's Judgment}

The next four questions concerned cataloger's judgment, not in the traditional sense of the phrase, but rather in terms of the judgment calls that catalogers have to make when they have no clear guidelines for cataloging self-published items. While the inconsistency of the data on these items makes use of cataloger's judgment unavoidable, again, clearer guidelines would help. Such guidelines would probably reduce the need for cataloger's judgment.

In the authors' cataloging experience, self-published items generally need original cataloging and require more outside searching in order to properly catalog them. Therefore, they wanted to know if these items require more effort to catalog. They asked a question about this situation to see what other people thought about it, as well as to look for correlations between this question and the next question, which pertains to how often these items need original 
cataloging. As shown in table 7, although "the same effort" was the most popular answer, it is important to note that one-third of the survey respondents indicated that it takes more effort, which strongly suggests that it is more difficult to catalog these items compared to items from traditional publishers. The text box responses, shown below, also show a variety of required effort levels.

Table 7.

7. How much effort do you put into cataloging self-published items compared to items from traditional publishers?

\begin{tabular}{|l|l|l|}
\hline Answer & Response & Percentage \\
\hline Less effort & 31 & $8 \%$ \\
\hline The same effort & 236 & $59 \%$ \\
\hline More effort & 134 & $33 \%$ \\
\hline Total & 401 & $100 \%$ \\
\hline
\end{tabular}

Question 7: Selected text box responses

"Getting to be the same amount of effort as I become more firm in my decisions"

"The same effort ends up requiring more time, because the information isn't as available."

"If the author is from our community, we make more effort."

"More effort because they almost always need original cataloging."

"Effort will vary from item to item depending on the nature of the material."

The authors have observed that self-published items usually need original cataloging.

Were other catalogers making this observation as well? They asked a question to find out. As shown in table 8, they were. "Mostly original records" was the top response by a significant margin. The selected text box responses, shown below, backed up the answers to the survey question.

Table 8.

8. How often do you create original records for self-published items?

\begin{tabular}{|l|l|l|}
\hline Answer & Response & Percentage \\
\hline Mostly original records & 253 & $63 \%$ \\
\hline
\end{tabular}




\begin{tabular}{|l|l|l|}
\hline Some original records & 117 & $29 \%$ \\
\hline Very few original records and mostly copy records & 30 & $7 \%$ \\
\hline No original records & 1 & $0 \%$ \\
\hline Total & 401 & $100 \%$ \\
\hline
\end{tabular}

Question 8: Selected text box responses

"It's very rare for us to find existing records for these items."

"Most of our self pubs are local, so this involves original cataloging."

"Almost always original records."

"Other than original, I tend to update/enhance existing brief vendor records for selfpublished items (very minimal information - often just ISBN and title etc."

The authors have noticed that self-published items can be of varying quality. John Luther Adams's Pulitzer Prize-winning orchestral work Become Ocean was self-published by his Taiga Press. ${ }^{14}$ At the opposite end of the spectrum, someone could self-publish something as ordinary as, for instance, a compendium of entries in their own blog. Are other catalogers looking at the quality of these items? If so, are they questioning whether or not these items belong in their libraries? The survey's ninth question was asked to find out. Just under half of the respondents, it turns out, consider whether or not the items should be added to the catalog (table 9), even if their role in the library is limited to cataloging.

\section{Table 9.}

9. When cataloging self-published items, do you ever consider whether or not they should be added to the catalog?

\begin{tabular}{|l|l|l|}
\hline Answer & Response & Percentage \\
\hline No & 203 & $51 \%$ \\
\hline Yes, but I keep my concerns to myself & 76 & $19 \%$ \\
\hline Yes, and I report items that shouldn't be added, but they get added anyway & 17 & $4 \%$ \\
\hline $\begin{array}{l}\text { Yes, and I report items that shouldn't be added, and they do not get added at least } \\
\text { some of the time }\end{array}$ & 101 & $25 \%$ \\
\hline Total & 397 & $100 \%$ \\
\hline
\end{tabular}


The text box responses, shown below, offered further insights. While some catalogers specifically do not do collection development, such as the first one quoted below, others have some level of responsibility for making collection-development decisions, such as the next two.

Question 9: Selected text box responses

"I'm just a cataloger. I don't do collection development or management."

"I am chief policy maker for music items."

"I also oversee collection development..."

"It is often difficult for our selection staff to know an item is self-published before it arrives.

Our book vendors do not always make it clear on their websites."

"I keep a list of online reprint self-publishers to avoid."

"Faculty requests always override our quality concerns."

Adding a note pertaining to an item's self-published status is a way that catalogers could clearly mark a record as being for a self-published item. Sometimes the publication information on the item has a written statement which indicates that it is self-published. The authors wanted to know if catalogers are transcribing that information if present on the item or adding it even if it is not on the item. While a majority of survey respondents do not choose to add additional notes regarding an item's publication status (table 10), about one-third of them always or sometimes add such notes.

Table 10.

\begin{tabular}{|l|l|l|}
\hline 10. Do you ever add any notes pertaining to an item's self-published status? \\
\hline Answer & Response & Percentage \\
\hline Always & 27 & $7 \%$ \\
\hline Sometimes & 100 & $25 \%$ \\
\hline Never & 273 & $68 \%$ \\
\hline Total & 400 & $100 \%$ \\
\hline
\end{tabular}

Based on the text box responses, shown below, catalogers who do create notes pertaining to an item's self-published status do so in a fairly straightforward manner. They usually put the term "self-published" in a note when they see that exact wording on the item. 
Question 10: Selected text box responses

"Generally, if item is explicitly identified as self-published we quote that identification directly."

"I have a stack of self-published books waiting to be cataloged now. I am considering adding a 500 note saying, 'This book is self-published' just so that information is there. I don't see any reason not to add it."

"Add a note about it being self-published."

"Self-published"

"I add a "local author" note to the item."

\section{Submitted MARC Record Analysis \& Comments Question}

The survey's eleventh question is its most important as it compares existing catalog records with the survey responses. The question read, "If you catalog self-published items in OCLC, please provide OCLC numbers for representative examples of the records you create." OCLC numbers for 357 MARC records were submitted and a wide variety of information from the records was entered into a spreadsheet, including format, publication firm when present, and type of library, to name three. The result of this process was a rich data set that can be analyzed in many ways. As an example, almost all of the records examined were created by either academic or public libraries (table 11a), which is consistent with the survey's first question.

Table 11a.

\begin{tabular}{|l|l|}
\hline 11a. Records by the type of library that created them & Response \\
\hline Type of Libraries & 203 \\
\hline Academic & 100 \\
\hline Public & 54 \\
\hline Special & 357 \\
\hline Total OCLC Records Examined & \\
\hline
\end{tabular}

The authors compared the data that they received from the submitted OCLC records with the data they gathered from two of the other survey questions. From their analysis of the OCLC records that the survey respondents submitted, although firm name appears much more often in 
the records' publisher area (MARC 260/264 subfield b), one-third of submitted records show that creator name is recorded as the publisher (table 11b), similar to the survey's fourth question. It is important to see that the creator of the works is being recorded in the publication area, perhaps because catalogers believe the creator has more control over the self-publication process, as explained earlier in the authors' version of defining self-publishing.

Table 11b.

\begin{tabular}{|l|l|}
\hline 11b. Records by how the publisher was recorded & Response \\
\hline Publication Area & 221 \\
\hline $\begin{array}{l}\text { Firm Name } \\
\text { (with brackets or without) }\end{array}$ & 111 \\
\hline $\begin{array}{l}\text { Creator's Name } \\
\text { (with brackets or without) }\end{array}$ & 20 \\
\hline Both & 25 \\
\hline Blank / [Publisher not identified] & 357 \\
\hline Total OCLC Records Examined & \\
\hline
\end{tabular}

The authors also compared the dates of the records that they analyzed with the survey's sixth question. Like the sixth question, their analysis of the records showed that the dates on these items tend to be unclear. Out of 357 records, 272 of the records had a publication date (table 11c). 187 of 272 records had a date in brackets, meaning that they were either inferred from another sort of date, such as a copyright date, or established by a cataloger's outside research. For that matter, at least some of the 85 publication dates that are not in brackets may be duplicated copyright dates as well. The 85 records that had no publication date almost always had copyright, distribution, production, or manufacture dates, but no publication date.

Table 11c

11c. Records by how the publication date was recorded

Publication Date

Publication Date With Brackets
Response

187 


\begin{tabular}{|l|l|}
\hline Publication Date Without Brackets & 85 \\
\hline No Publication Date & 85 \\
\hline Total OCLC Records Examined & 357 \\
\hline
\end{tabular}

The authors searched two major name authority databases, the Virtual International Authority File (VIAF) and the Library of Congress Name Authority File (LCNAF), for the creators of the self-published items (table 11d). Although the majority of the survey respondents were from the United States, some of the international self-publishing authors that they cataloged could have been only existing in VIAF and not in LCNAF. Therefore, both databases were searched in order to be safe. A significant majority of the names were in neither of the databases. This is a problem, since it makes these creators less visible and could lead to a single creator's name being recorded in different ways by different libraries. The absence of creator names in these two major authority databases could also mean that authority records for these names have only been created in local library databases and not uploaded to these major databases. Whether these names are only important to local communities or to the entire world, the authors believe that they should be made more visible to everyone. This is one of many aspects of this topic that need to be considered in more depth by better cataloging guidelines.

Table 11d.

\begin{tabular}{|c|c|}
\hline \multicolumn{2}{|c|}{ 11d. Records by author presence in authority files } \\
\hline Name Analysis & Response \\
\hline Neither VIAF nor LCNAF & 200 \\
\hline VIAF \& LCNAF & 147 \\
\hline LCNAF & 2 \\
\hline VIAF & 3 \\
\hline No Name & 5 \\
\hline Total OCLC Records Examined & 357 \\
\hline
\end{tabular}


Two of the MARC records submitted by the survey respondents illustrate the variety of ways in which people are cataloging self-published items using their best judgments to make these items as visible as they can. (The creators of these records gave permission to use their records in this article.) The first record is for a CD by the Portland, Oregon-based rock musician Ryan VanDordrecht (table 11e). ${ }^{15}$ It is important to note that VanDordrecht is transcribed as the publisher in the first MARC 264 field, which clearly indicates that he is a self-publisher. Also, the publication location is a guess by the cataloger based on where VanDordrecht lives and is put in brackets, which is a much better practice than recording "Place of publication not identified" in brackets. VanDordrecht has relationship designators as the composer and performer in his 100 field, which opens up the possibility that he could have a third one as the "self-publisher" since he also has that role. Creating "self-publisher" as an Resource Description and Access (RDA) relationship designator opens up a debate as to how useful it would be for the end user or for anyone keeping track of self-published materials in their catalog. There is also a streaming version of the album, which is available at VanDordrecht's website. ${ }^{16}$ It is possible to have a note about the availability of the streaming version in the catalog record as well, but this is another debate. Overall, this record shows good practices to make the item more visible.

Table 11e.

\begin{tabular}{|c|c|}
\hline \multicolumn{2}{|c|}{ 11e. Excerpt from a record for a self-published CD } \\
\hline 1001 & |a VanDordrecht, Ryan, |e composer, |e performer. \\
\hline 24510 & |a Beast of love / |c Ryan VanDordrecht. \\
\hline $264 \_1$ & |a [Portland, Ore.] : |b Ryan VanDordrecht, |c [2014] \\
\hline $264 \_4$ & |c (P2014 \\
\hline 300 & |a 1 audio disc : |b CD audio, digital ; |c $43 / 4$ in. \\
\hline 500 & a Compact disc. \\
\hline
\end{tabular}




\begin{tabular}{|l|l|}
\hline $500 \_$ & $\mid$a Title from container. \\
\hline $5110 \_$ & $\mid$a Performed by Ryan VanDordrecht, Rian Lewis, Brian Koch, Troy Walstead, and Jen Dashney. \\
\hline 50500 & $\begin{array}{l}\mid \mathrm{t} \text { Hard lover -- } \mid \mathrm{t} \text { Great American life -- } \mid \mathrm{t} \text { I ain't coming home tonight -- } \mid \mathrm{t} \text { Wild ones -- } \mid \mathrm{t} \text { You got } \\
\text { Travelin' on -- } \mid \mathrm{t} \text { Hard lover -- One more cigarette -- } \mid \mathrm{t} \text { Last one to know. }\end{array}$ \\
\hline $650 \_0$ & $\mid$ a Rock music |y 2011-2020. \\
\hline $650 \_0$ & $\mid$ a Rock music $\mid z$ Oregon $\mid z$ Portland. \\
\hline
\end{tabular}

The second record that is shown as an example is for a book by best-selling authors Sarina Bowen ${ }^{17}$ and Elle Kennedy (table 11f). ${ }^{18}$ There are three 264 fields in the record. As in the previous record example, this record also makes it clear that Bowen and Kennedy are the self-publishers separately transcribed in two subfield bs in the first 264 . The second 264 credits the firm (in this case, CreateSpace) as the manufacturer, with a third 264 for the copyright date. The dates are all the same in the three $264 \mathrm{~s}$, and the publication date is inferred from the copyright date. In addition, the first 264 field gives the publication location as where the authors live in brackets with a question mark, which shows the cataloger's effort to record something meaningful in this space rather than leaving it blank. All of these are good practices which makes the item more visible and accessible. The roles of the authors and firm are further explained in the first 500 field, with an additional 500 field that explains the second 264 field. It is important to note that first 500 field also indicates that the book is self-published. The second 500 indicates that the manufacture date and place is taken from the end of the book, which is an unusual place that is not generally considered as a source of information. Overall, both records show catalogers making their best efforts to transcribe the information available in unusual places for publication information.

Table 11f.

11f. Excerpt from a record for a self-published book 


\begin{tabular}{|l|l|}
\hline $100 \_1$ & $\mid$ a Bowen, Sarina, $\mid \mathrm{e}$ author. \\
\hline 24510 & $\mid \mathrm{a}$ Him $/ \mid \mathrm{c}$ Sarina Bowen, Elle Kennedy. \\
\hline $264 \_1$ & $\mid \mathrm{a}$ [United States?] : $\mid \mathrm{b}$ S. Bowen, $\mid \mathrm{b}$ E. Kennedy, $\mid \mathrm{c}[2015]$ \\
\hline $264 \_2$ & $\mid \mathrm{a}$ Lexington, KY : $\mid \mathrm{b}[$ Manufactured by CreateSpace], $\mid \mathrm{c} 2015$. \\
\hline $264 \_4$ & $\mid \mathrm{c}$ @ 2015 \\
\hline $300 \_$ & $\mid \mathrm{a} 352$ pages $; \mid \mathrm{c} 21 \mathrm{~cm}$ \\
\hline $336 \_$ & $\mid \mathrm{a}$ text $\mid \mathrm{b}$ txt $\mid 2$ rdacontent \\
\hline $337 \_$ & $\mid$a unmediated $|\mathrm{b} \mathrm{n}| 2$ rdamedia \\
\hline $338 \_$ & $\mid$a volume $\mid \mathrm{b}$ nc $\mid 2$ rdacarrier \\
\hline $500 \_$ & $\mid$a Work self-published by authors using CreateSpace. \\
\hline $500 \_$ & $\mid$a Place and date of manufacture taken from end of work and may differ between printings. \\
\hline
\end{tabular}

The survey's twelfth, and final, question read, "Please provide any further comments or concerns that you have about cataloging self-published items here." A small sampling of what they had to say is shown below. The authors of this article were particularly pleased to see opinions such as the one from the third person quoted here.

Question 12: Selected responses

"I should add often we catalog self-published local authors (books) or music groups (cds) to support local authors/musicians in our community. We often add copies of these local items to our special collections room as well as circulating copies."

"We have some very rare and unusual recordings done by people who went on to be famous as musicians or in other fields."

"I am glad to see that you are researching this topic, which I think needs to be tackled on a much wider scale throughout the cataloguing community. Together, we should make up suggested guidelines for templates or more efficient ways of cataloging these items." "We urge the "publishers" to provide better information and create a better product." "Too many self-published works are lacking the information necessary to properly catalog them..."

\section{DISCUSSION \& SUGGESTIONS FOR BEST PRACTICES}

To quote the third person quoted in the preceding question, the authors' work as a whole shows that "more efficient ways of cataloging [self-published] items" are urgently needed. The 
WorldCat records and the survey results show that catalogers have been making a sincere effort to catalog these items, although the lack of information on these items makes these efforts challenging. The records and results also show that the cataloging of these items has been inconsistent. As these items make their way into libraries in increasing numbers, the need for best practices to catalog them increases as well. The records and survey results, particularly the records excerpted in tables $11 \mathrm{e}$ and $11 \mathrm{f}$, show patterns that the authors believe can be the foundation of better ways of cataloging these items. With that in mind, they have a number of suggestions for what best practices for cataloging self-published items should address.

Catalogers and other librarians are not the only people who should help to shape those best practices. Creators are involved in their items' publication process and could create better bibliographic information that catalogers need. Public and academic libraries frequently host self-publishing initiatives and reach out to creators of self-published items in their communities. Public-services librarians could work with catalogers in order to inform and educate these creators about how to create more useful data for cataloging. This would make these items much easier to catalog and more visible and accessible to everyone, including potential buyers. Therefore, when constructing best practices for the cataloging of self-published items, the ways in which creators are publishing and distributing them and the ways in which library users would like to access them should be considered as well.

The survey's first three questions bring up a number of related issues. While the first question makes it clear that self-published items are every type of library's concern, best practices should consider cataloging of self-published items could differ in various types of libraries, as, for instance, public libraries may need to handle them differently from academic libraries. Similarly, the third question shows that libraries are collecting self-published items in a 
variety of formats, making it necessary for best practices to address the differences between formats. The second question suggests that some libraries are only cataloging self-published items locally and not sharing them in databases such as WorldCat. This is concerning, as it limits these items' accessibility, not only for library users, but for other catalogers who may be seeking common ground for creating guidelines for cataloging self-published items.

As shown in the survey's fourth question, the question of what to record in the publisher area in records for self-published items is a complicated one. How much publishing responsibility does the creator take for a self-published item, and how much does the firm take? Should the creator's name be given preference, or the firm name, or should both names be routinely recorded in the publication area? For the most part, catalogers are making an effort to put something meaningful in that space, an effort that, like cataloging these items in shared databases, helps make the items visible. This takes more time than putting "Publisher not identified" in brackets would, as it requires doing at least a little outside research. However, catalogers are still struggling to decide between recording the creator or the firm as the publisher, which shows that there is a need for clearer guidelines. Recording both the creator name and firm name is possible, particularly for catalogers using RDA. The authors have seen that the best records tend to have both names. The record shown in table $11 \mathrm{f}$ is a good example of this practice. Whether they follow this practice or not, catalogers should consider what would best help library users find these items.

Recording the place of publication for self-published items is similarly complicated. To a significant extent, this is a matter of cataloger's judgment due to the inconsistency or absence of information on such items. As with the publisher, though, catalogers are making an effort to put something meaningful in this space by guessing and using brackets, which improves the items' 
visibility. Putting "Place of publication not identified" in brackets is clearly the last resort. Catalogers should remember that library users will most likely benefit if there is at least the country name (based on the creator's nationality or residence) or printing location in brackets. The record shown in table $11 \mathrm{f}$ illustrates this.

The survey results indicate that publication dates for self-published items need to be addressed as well, as they are usually absent from the item. In their analysis of the submitted records for items in all formats, the authors have seen that there is not always a publication date on an item, but there is almost always a production, manufacture, distribution, or copyright date. The text box responses to the sixth question show that catalogers are frequently inferring a publication date from the copyright date when the latter is present. In fact, doing this is clearly suggested and underlined in RDA, according to an LC-PCC Policy Statement on the topic. ${ }^{19}$ Both the text box responses and the submitted records show that, again, there is a high effort from catalogers to put some sort of date in the publication area instead of putting "Date of publication not identified" in brackets. This effort can involve using printing dates from the bottom of the last page of a self-published book, which is an unusual place to get such information. The responses to the sixth question show that clearer guidelines would help here as well, especially when an item is print-on-demand and only has a printing date. The record shown in table $11 \mathrm{f}$ features a publication date inferred from a copyright date, as well as a manufacture date.

The survey's seventh question asks whether catalogers put more or less effort into cataloging self-published items than they do into items for traditional publishers. It is important to note that less effort should not be perceived as the item in question having less value, although there is a correlation between them. Some of the survey respondents indicated in the seventh 
question's text box responses that they spent more time on items that are more beneficial to their community. Based on these responses, as well as the answers to the question itself, these items may receive more effort and can take more time since they lack complete publication information and usually need original cataloging. Whether they question the value of these items or not, catalogers are putting in the time and effort to make these items visible and accessible. On the other hand, the lack of guidelines for how to catalog such items also slows down catalogers, resulting in these items needing quite a bit of time and effort. As the first quote shown above mentioned, though, it gets easier as one gains more experience, and having clearer guidelines would make it easier as well.

The survey's eighth question dealt with how often catalogers have to create original records for self-published items. Between this question and the previous one, it is clear that selfpublished items require more work compared to items from traditional publishers, work that catalogers are putting in to make these items as visible as possible. Sharing of all records created for self-published items, as discussed in the survey's second question, would be particularly helpful, as any sort of original cataloging can be highly time-consuming. Better guidelines for cataloging these items would help as well, as they would with all aspects of this topic.

While the research behind this article is primarily focused on cataloging, the authors are also interested in the role that catalogers play, or could play, in collection development. The survey's ninth question shows that, due to their varying quality, self-published items may blur the line between cataloging and collection development. As one of the text box responses to this question points out, collection-management personnel might not always catch that an item is self-published, an area in which catalogers can help. The provenance or purpose of these selfpublished items sometimes plays a role as these items take their places in libraries. Sometimes, 
for local authors such as students, professors, or members of the community, there is a policy to catalog them regardless of the quality of the item. In this case, catalogers can indicate the item's provenance in the record or add note fields indicating that there is no bibliography or index to give a clue to library users about how scholarly these items are.

As described in the survey's tenth question, clearly marking a record as being for a selfpublished item is a useful practice that could benefit library users. For instance, it is very important for musicians to know who published the score to a work they are studying or performing, as well as which edition of the score they have. Scholars in other fields have similar concerns and would find it useful to know if the item was published as a print-on-demand item and which printing company printed it. If catalogers mark records as being for self-published items, when and how should they do so? According to the text box responses for the tenth question, catalogers sometimes put the term "self-published" in a note when they see it on the item. It is possible to add terms related to self-publishing (such as "Print-on-demand items" or "Self-published items") to a controlled vocabulary, such as the Library of Congress Genre/Form Terms. Whether an additional note is created or a controlled-vocabulary term is used, the way in which a record is marked as being for a self-published item could be standardized, which would be useful to scholars.

These items tend to exist in a variety of formats, editions, and printings. Books and scores can have both print and electronic versions, albums can be released both on CD and as digital downloads, and anything that is print-on-demand can have several different printing dates. Should catalogers create separate records for each of these, or should they create one record for a given item? If they create separate records, Linked Data might be the way to connect all of these 
versions to each other. If they create one record, the record shown in table $11 \mathrm{f}$ might be a model for how to do so.

In addition to the matters described earlier in this section, best practices for cataloging self-published items need to consider other matters that were not discussed in this article. Within the records themselves, these include, but are not limited to, the presence or absence of ISBNs, MARC encoding levels, and the absence of summary notes (MARC field 520) which impedes classification and the assignment of subject headings. More broadly, one could also consider why self-published authors, as shown in table $11 \mathrm{~d}$, frequently do not have national authority records for their names; it could be due to a lack of training, or it could be due to local policies to not create such records. One can also gain further insight into self-published items by taking a closer look at the actions of self-publishing creators. Each of these matters could be the topic of an additional research project as well. The authors strongly encourage further research in these areas.

Today, libraries are becoming part of the self-publishing scene, not only by acquiring self-published items, but by supporting content creators with self-publishing initiatives. Catalogers are part of this scene as well, since they are responsible for making these items visible to library users. The goal of the authors of this article is to point out that the self-publishing phenomenon needs further research, especially from the cataloger's perspective. They hope that this article was able to serve as a voice for the catalogers who took this survey and submitted their records for analysis. The authors' survey results, record analysis, and literature review all show that it is time for catalogers to approach this issue more closely and look at the specific ways in which people are cataloging self-published items. Perhaps more conversation on this 
topic can lead to the creation of best practices for cataloging these items, so that they may be as visible and accessible as possible for library users.

\section{NOTES}

1. The conferences where this project was presented were the Music Library Association's Midwest Chapter's annual meeting in October 2015, the American Library Association's Midwinter Meeting in January 2016, the Music OCLC Users Group's annual meeting in March 2016, the Music Library Association's annual meeting in March 2016, the International Association of Music Libraries' annual congress in July 2016, and the International Federation of Library Associations' World Library and Information Congress in August 2016.

2. "Self-publish | Definition of Self-publish by Merriam-Webster," Merriam-Webster Incorporated, accessed April 10, 2017, https://www.merriam-webster.com/dictionary/selfpublish.

3. Michael Saffle, "Self-publishing and Musicology: Historical Perspectives, Problems, and Possibilities.” Notes 66, no. 4 (June 2010): 726-738, http://dx.doi.org/10.1353/not.0.0376. 4. Juris Dilevko and Keren Dali, “The Self-Publishing Phenomenon and Libraries." Library \& Information Science Research 28, no. 2 (2006): 208-234, http://dx.doi.org/10.1016/j.lisr. 2006.03.003.

5. Jana Bradley, Bruce Fulton, and Marlene Helm, "Self-Published Books: An Empirical 'Snapshot."' Library Quarterly 82, no. 2 (2012): 107-140, Library, Information Science \& Technology Abstracts, EBSCOhost. 
6. Robert P. Holley, "Self-Publishing and Bibliographic Control," in Self-Publishing and Collection Development: Opportunities and Challenges for Libraries, ed. Robert P. Holley (West Lafayette, Indiana: Purdue University Press, 2015), 113-123.

7. "RUSA Library Publishing Toolkit - A Service of the Reference and User Services Association (RUSA)," Reference and User Services Association, accessed March 24, 2018, https://rusapubtools.wordpress.com/.

8. Heather Moulaison Sandy, "The Role of Public Libraries in Self-Publishing: Investigating Author and Librarian Perspectives," Journal of Library Administration 56, no. 8 (2016): 893912, http://dx.doi.org/10.1080/01930826.2015.1130541.

9. "Zine | Definition of Zine by Merriam-Webster," Merriam-Webster Incorporated, accessed February 14, 2019, https://www.merriam-webster.com/dictionary/zine.

10. Heidy Berthoud, "Going to New Sources: Zines at the Vassar College Library," Serials Librarian 72, nos. 1-4 (2017): 49-56, http://dx.doi.org/10.1080/0361526X.2017.1320867.

11. Kent Underwood, "Scores, Libraries, and Web-Based, Self-Publishing Composers." Notes 73, no. 2 (December 2016): 205-240, General OneFile, Gale.

12. Charles Peters, "Acquiring New Music from Unconventional Sources: PDF Copies in the Library," paper presented at the International Association of Music Libraries Annual Congress, Riga, Latvia, June 2017.

13. Anne Adams and Morris Levy, "Cataloging Scores in an Age of Print on Demand," paper presented at the Music OCLC Users Group Annual Meeting, Orlando, FL, February 2017. 14. "2014 Pulitzer Prize Winners \& Finalists - The Pulitzer Prizes," Columbia University, accessed June 18, 2018, http://www.pulitzer.org/prize-winners-by-year/2014. 
15. "Bio -- Ryan VanDordrecht," Ryan VanDordrecht, accessed June 18, 2018, http://www.ryanvandordrecht.com/bio/.

16. "Beast of Love -- Ryan VanDordrecht," Ryan VanDordrecht, accessed June 18, 2018, http://www.ryanvandordrecht.com/music/.

17. "Bio -- Sarina Bowen,” Sarina Bowen, accessed June 18, 2018, https://www.sarinabowen.com/bio/.

18. “About Elle | Elle Kennedy,” Elle Kennedy, accessed June 18, 2018, https://www.ellekennedy.com/about-elle/.

19. “LC-PCC PS for 2.8.6.6," RDA Toolkit, accessed August 29, 2017, http://access.rdatoolkit.org/document.php?id=lcpschp2\&target=lcps2-1467\#lcps2-1467 